\title{
Predictors of in-hospital mortality following major lower extremity amputations in type 2 diabetic patients using artificial neural networks
}

Ana Lopez-de-Andres ${ }^{1 *}$, Valentin Hernandez-Barrera ${ }^{2}$, Roberto Lopez², Pablo Martin-Junco², Isabel Jimenez-Trujillo ${ }^{1}$, Alejandro Alvaro-Meca', Miguel Angel Salinero-Fort ${ }^{3}$ and Rodrigo Jimenez-Garcia ${ }^{1}$

\begin{abstract}
Background: Outcome prediction is important in the clinical decision-making process. Artificial neural networks (ANN) have been used to predict the risk of post-operative events, including survival, and are increasingly being used in complex medical decision making. We aimed to use ANN analysis to estimate predictive factors of in-hospital mortality (IHM) in patients with type 2 diabetes (T2DM) after major lower extremity amputation (LEA) in Spain.

Methods: We design a retrospective, observational study using ANN models. We used the Spanish National Hospital Discharge Database to select all hospital admissions of major LEA procedure in T2DM patients. Main outcome measures: Predictors of IHM using 4 ANN models: i) with all discharge diagnosis included in the database; ii) with all discharge diagnosis included in the database, excluding infectious diseases; iii) comorbidities included in the Charlson Comorbidities Index; iv) comorbidities included in the Elixhauser Comorbidity Index.

Results: From 2003 to 2013, 40,857 major LEAs in patients with T2DM were identified with a 10.0\% IHM. We found that Elixhauser Comorbidity Index model performed better in terms of sensitivity, specificity and precision than Charlson Comorbidity Index model (0.7634 vs $0.7444 ; 0.9602$ vs $0.9121 ; 0.9511$ vs 0.888 , respectively). The area under the ROC curve for Elixhauser comorbidity model was $91.7 \%$ (95\% Cl 90.3-93.0) and for Charlson comorbidity model was 88.9\% (95\% Cl; 87.590.2) $p=0.043$. Models including all discharge diagnosis with and without infectious diseases showed worse results. In the Elixhauser Comorbidity Index model the most sensitive parameter was age (variable sensitive ratio [VSR] 1.451) followed by female sex (VSR 1.433), congestive heart failure (VSR 1.341), renal failure (VSR 1.274) and chronic pulmonary disease (VSR 1.266).

Conclusions: Elixhauser Comorbidity Index is a superior comorbidity risk-adjustment model for major LEA survival prediction in patients with T2DM than Charlson Comorbidity Index model using ANN models. Female sex, congestive heart failure, and renal failure are strong predictors of mortality in these patients.
\end{abstract}

Keywords: Major lower extremity amputation, Type 2 diabetes, Charlson Comorbidity Index, Elixhauser Comorbidity Index, In-hospital mortality, Artificial neural networks

\footnotetext{
* Correspondence: ana.lopez@urjc.es

${ }^{1}$ Preventive Medicine and Public Health Teaching and Research Unit, Health

Sciences Faculty, Rey Juan Carlos University, Avda. de Atenas s/n, 28922

Alcorcón, Comunidad de Madrid, Spain

Full list of author information is available at the end of the article
} 


\section{Background}

In the previous decade, incidence rates of diabetes-associated amputations have significantly decreased [1-5]. However, a major lower extremity amputation (LEA) is associated with a reduction of long-term survival and quality of life [6, 7].

In Spain, more than 5,000 major LEAs are performed yearly, 57\% in patients with type 2 diabetes (T2DM) [8]. Despite improvements in long-term outcome, inhospital mortality (IHM) following major LEA in patients with T2DM has remained stable from 2001 to 2012 with figures of $9.7 \%$ and $9.5 \%$ respectively $[8,9]$.

Outcome prediction is important in the clinical decision-making process. Older age, renal failure and congestive heart failure have been identified as independent factors for operative mortality following major LEA in Veterans Administration patients [10]. Wise et al. (2016) reported that preoperative septic shock and thrombocytopenia are independent risk factors for 30-day mortality after major LEA [11]. Other authors have described that age and vascular disease in patients with T2DM are important predictors that contribute to increase the mortality after major LEA [12]. However, to our knowledge, there are no studies investigating the predictive factors of in-hospital operative mortality in T2DM patients following major LEA.

Artificial neural networks (ANN) have been used to predict the risk of post-operative events, including survival, exploring complex relationships between preoperative variables survival in different surgical settings and are increasingly being used in complex medical decision making [13-16].

The aim of our study was to use ANNs analysis to estimate predictive factors of IHM in patients with T2DM after major LEA in Spain. We assessed the performance indices for ANN models in four scenarios: i) with all discharge diagnosis included in the database; ii) with all discharge diagnosis included in the database, excluding infectious diseases; iii) comorbidities included in the Charlson Comorbidities Index (CCI) and iv) comorbidities included in the Elixhauser Comorbidity Index (ECI).

\section{Methods}

We have been used the Spanish national hospital database, from 2003 to 2013 to identify predictive factors of IHM in type 2 diabetic patients after major LEA. The database contained variables like sex, date of birth, admission date, discharge diagnoses (up to 14), procedures performed during the hospital stay (up to 20), length of hospital stay (LOHS) and IHM [17]. Diagnosis and procedures are codified according to the International Classification of Diseases, Ninth Revision, Clinical Modification (ICD-9-CM). Details on this database have been published previously $[18,19]$.
The study included all procedures of major amputation, defined as any LEA through or proximal to the ankle joint (ICD-9-CM codes 84.13-84.17) in discharges with a T2DM diagnosis (ICD-9-CM codes 250.x0; 250.x2) in any diagnosis position. We excluded all traumatic major LEAs (ICD-9-CM codes 895-897; 905.9; 928-929; 959 in any diagnosis field) and patients with type 1 diabetes (T1DM) (ICD-9-CM codes 250.x1; 250.x3).

The study sample included 40,857 patients who undergone major amputation procedure between January 1, 2003 and December 31, 2013.

\section{Development of the ANN models}

To provide a good quality predictive model, the database has been randomly splitted in three independent subsets: $60 \%$ of the entire database for training the neural network ( $n=24,513$ cases), $20 \%$ for selecting those models with better generalization capabilities ( $n=8,172$ cases) and $20 \%$ for testing the model $(n=8,172$ cases). The independent variables were age, sex, comorbidity and LOHS, and the dependent variable was outcome (IHM).

The ANN used in this study was a standard feedforward, back-propagation neural network in which each input layer received information from the data, then it passed through the hidden layers and, finally, it arrived to the output layer. We used the quasi-Newton method in order to carry out the learning process (training algorithm) [20] and we applied model selection to find the optimal number of neurons in the hidden layer [21].

We elaborated four models as follow: model 1) including all discharge diagnosis in the database; model 2) all discharge diagnosis included in the database, except infectious diseases (ICD-9-CM codes 001 to 139); model 3) comorbidities included in the CCI [22] and finally; model 4) comorbidities included in the ECI [22].

\section{Statistical analyses}

The unit of analysis was the individual patient with T2DM undergoing major LEA. A descriptive analysis was performed for all variables. Categories variables are shown as total numbers or proportions. Significant predictors were identified by bivariate analysis using chi square test, Student's $t$-test or Mann-Whitney $U$ test when appropriate ( $p<0.05,2$-tailed).

The predictive capabilities of the four models was analyzed using the area under the ROC curve (AUC) and the performance indices for ANN models described in Table 3 [23]. In this context, discrimination model is which to ability to distinguish patients who died from those who survived. Finally, once the model is trained, it can be studied the importance of the input variables by performing a sensitivity analysis. The sensitivity of an input variable is calculated 
dividing the sum squared error of the neural network responses without using the input variable by the sum squared error of the neural network responses using all the inputs. In this way, if the error without the input variable is lower than the error using all the inputs, the value of the sensitivity will be lower than 1 and if it is greater, the sensitivity will be greater than 1 , as described previously by Shi et al. [24].

To estimate the $95 \%$ confidence interval and to compare AUC we used EPIDAT 4.2 software applying the methods described by DeLong et al. [25, 26].

The design of the four ANNs was performed using the predictive analytics solution Neural Designer, developed by the authors of this work. Statistical analyses were performed using the Stata MP version 10.1 statistical package (StataCorp LP, College Station, TX).

\section{Sensitivity analysis}

In order to assess the possible misclassification of T1DM patients as T2DM or vice versa in the database the predictive capabilities of the CCI and the ECI were analyzed estimating the AUC including all patients with any diabetes ICD-9-CM codes (250.xx), beside Type $1 \mathrm{o}$ Type 2.

\section{Results}

Between January 1, 2003 and December 31, 2013, a total of 40,857 non-traumatic major LEAs (26,222 in men and 14,635 in women) corresponding to T2DM were identified in Spain. Almost $82 \%$ of the patients have $\geq 65$ years of age (mean age 73.77 years, SD 10.26 years).

We found that $10.0 \%(n=4,078)$ of the patients who died during the admission in hospital. The mean age of patients who died during their stay was significantly higher (76.58 years) than those survived (73.47 years).

The mean (SD) LOHS was similar, 23.10 (22.17) days in patients who died during their hospitalization and 23.78 (22.09) days in those who survive after the procedure $(P>0.05)$.

Table 1 shows the demographic characteristics and prevalence of comorbidities included in the CCI according to IHM after a major LEA in patients with T2DM.

We found that $68.83 \%$ of the patients had peripheral vascular disease, $17.49 \%$ have renal disease and $11.52 \%$ have chronic pulmonary disease these were the three more common chronic conditions.

In our study IHM in women with T2DM was more common than in diabetic men $(11.7 \%$ vs. $9.0 \%, p<0.05)$. IHM was significantly higher in older patients $(13.4 \%$

Table 1 Demographic characteristics and prevalence of comorbidities included in the Charlson Comorbidity Index according to IHM due to major LEA in patients with T2DM in Spain, 2003-2013

\begin{tabular}{|c|c|c|c|c|c|c|c|}
\hline \multirow[b]{2}{*}{ Men } & \multicolumn{2}{|c|}{ Prevalence } & \multicolumn{2}{|c|}{ Condition $1 \mathrm{HM} \%$} & \multicolumn{2}{|c|}{ No condition IHM\% } & \multirow{2}{*}{$\frac{p \text {-value }}{<0.001}$} \\
\hline & 26222 & 64.2 & 2363 & 9.0 & & & \\
\hline Women & 14635 & 35.8 & 1715 & 11.7 & & & \\
\hline$<50$ years & 805 & 2.0 & 33 & 4.1 & & & $<0.001$ \\
\hline $50-64$ years & 6702 & 16.4 & 439 & 6.6 & & & \\
\hline 65-79 years & 20334 & 49.8 & 1862 & 9.2 & & & \\
\hline$\geq 80$ years & 13016 & 31.9 & 1744 & 13.4 & & & \\
\hline Myocardial infarction & 2472 & 6.05 & 393 & 15.9 & 3685 & 9.6 & $<0.001$ \\
\hline Congestive heart failure & 4384 & 10.73 & 1020 & 23.3 & 3058 & 8.4 & $<0.001$ \\
\hline Peripheral vascular disease & 28120 & 68.83 & 2648 & 9.4 & 1430 & 11.2 & $<0.001$ \\
\hline Cerebrovascular disease & 3993 & 9.77 & 524 & 13.1 & 3554 & 9.6 & $<0.001$ \\
\hline Dementia & 2373 & 5.81 & 329 & 13.9 & 3749 & 9.7 & $<0.001$ \\
\hline Chronic pulmonary disease & 4706 & 11.52 & 570 & 12.1 & 3508 & 9.7 & $<0.001$ \\
\hline Rheumatoid disease & 523 & 1.28 & 51 & 9.8 & 4027 & 10.0 & 0.860 \\
\hline Peptic ulcer disease & 375 & 0.92 & 56 & 14.9 & 4022 & 9.9 & $<0.001$ \\
\hline Mild liver disease & 1114 & 2.73 & 149 & 13.4 & 3929 & 9.9 & $<0.001$ \\
\hline Hemiplegia or paraplegia & 248 & 0.61 & 22 & 8.9 & 4056 & 10.0 & 0.559 \\
\hline Renal disease & 7147 & 17.49 & 1054 & 14.7 & 3024 & 9.0 & $<0.001$ \\
\hline Any malignancy & 854 & 2.09 & 95 & 11.1 & 3983 & 10.0 & 0.260 \\
\hline Moderate or severe liver disease & 202 & 0.49 & 48 & 23.8 & 4030 & 9.9 & $<0.001$ \\
\hline Metastatic solid tumor & 157 & 0.38 & 31 & 19.7 & 4047 & 9.9 & $<0.001$ \\
\hline AIDS/HIV & 27 & 0.07 & 2 & 7.4 & 4076 & 10.0 & 0.655 \\
\hline
\end{tabular}

$P$ value comparing IHM between those with and without the condition. Any malignancy, including lymphoma and leukemia, except malignant neoplasm of skin 
in $\geq 80$ years vs. $4.1 \%$ in $<50$ years). Patients with myocardial infarction, congestive heart failure, peripheral vascular disease, cerebrovascular disease, dementia, chronic pulmonary disease, peptic ulcer disease, mild liver disease, renal disease, moderate or severe liver disease or metastatic solid tumour had significantly higher IHM than those without these conditions (Table 1). Over $20 \%$ of the patients suffering moderate or severe liver disease (23.8\%) and congestive heart failure (23.3\%) died in the hospital after a major LEA.

As can be seen in Table 2 when we analyse comorbidity included in the ECI we find that peripheral vascular disease and hypertension (47\% complicated and $1.8 \%$ uncomplicated) were the more prevalent diseases in diabetic patients who underwent LEAs. All patients with any ECI (except those with paralysis, hypothyroidism, peptic ulcer disease excluding bleeding, AIDS/HIV, rheumatoid arthritis/collagen vascular diseases, obesity, blood loss anemia, alcohol abuse or drug abuse) have significantly higher IHM than those without these conditions (Table 2). Beside congestive heart failure (23.3\%) patients suffering fluid and electrolyte disorders (29.9\%), coagulopathy $(24.8 \%)$ and pulmonary circulation disorders (21.6\%) showed the highest IHM.

The ANN-based approaches provided the 3-layer networks and the relative weights of neurons used for predicting IHM. Table 3 shows the ANN models in terms of binary classification tests. The data analysis showed that ANN model 3 and ANN model 4 have the best

Table 2 Prevalence of comorbidities included in the Elixhauser Comorbidity Index according to IHM due to major LEA in patients with T2DM in Spain, 2003-2013

\begin{tabular}{|c|c|c|c|c|c|c|c|}
\hline \multirow{2}{*}{$\frac{\text { Comorbidities }}{\text { Congestive heart failure }}$} & \multicolumn{2}{|c|}{ Prevalence } & \multicolumn{2}{|c|}{ Condition IHM } & \multicolumn{2}{|c|}{ No condition IHM } & \multirow{2}{*}{$\frac{p \text {-value }}{<0.001}$} \\
\hline & 4384 & 10.7 & 1020 & 23.3 & 3058 & 8.4 & \\
\hline Cardiac arrhythmias & 7552 & 18.5 & 1079 & 14.3 & 2999 & 9.0 & $<0.001$ \\
\hline Valvular disease & 1716 & 4.2 & 244 & 14.2 & 3834 & 9.8 & $<0.001$ \\
\hline Pulmonary circulation disorders & 500 & 1.2 & 108 & 21.6 & 3970 & 9.8 & $<0.001$ \\
\hline Peripheral vascular disorders & 28120 & 68.8 & 2648 & 9.4 & 1430 & 11.2 & $<0.001$ \\
\hline Hypertension, uncomplicated & 19204 & 47.0 & 1616 & 8.4 & 2462 & 11.4 & $<0.001$ \\
\hline Hypertension, Complicated & 5220 & 12.8 & 720 & 13.8 & 3358 & 9.4 & $<0.001$ \\
\hline Paralysis & 248 & 0.6 & 22 & 8.9 & 4056 & 10.0 & 0.559 \\
\hline Other neurological disorders & 1268 & 3.1 & 174 & 13.7 & 3904 & 9.9 & $<0.001$ \\
\hline Chronic pulmonary disease & 4706 & 11.5 & 570 & 12.1 & 3508 & 9.7 & $<0.001$ \\
\hline Hypothyroidism & 867 & 2.1 & 84 & 9.7 & 3994 & 10.0 & 0.771 \\
\hline Renal failure & 7125 & 17.4 & 1052 & 14.8 & 3026 & 9.0 & $<0.001$ \\
\hline Liver disease & 1316 & 3.2 & 197 & 15.0 & 3881 & 9.8 & $<0.001$ \\
\hline Peptic ulcer disease excluding bleeding & 223 & 0.5 & 23 & 10.3 & 4055 & 10.0 & 0.868 \\
\hline AIDS/HIV & 27 & 0.1 & 2 & 7.4 & 4076 & 10.0 & 0.655 \\
\hline Lymphoma & 70 & 0.2 & 2 & 2.9 & 4076 & 10.0 & 0.047 \\
\hline Metastatic cancer & 157 & 0.4 & 31 & 19.7 & 4047 & 9.9 & $<0.001$ \\
\hline Solid tumor without metastasis & 817 & 2.0 & 107 & 13.1 & 3971 & 9.9 & 0.003 \\
\hline Rheumatoid arthritis/collagen vascular diseases & 686 & 1.7 & 72 & 10.5 & 4006 & 10.0 & 0.650 \\
\hline Coagulopathy & 270 & 0.7 & 67 & 24.8 & 4011 & 9.9 & $<0.001$ \\
\hline Obesity & 1898 & 4.6 & 195 & 10.3 & 3883 & 10.0 & 0.663 \\
\hline Weight Loss & 542 & 1.3 & 106 & 19.6 & 3972 & 9.9 & $<0.001$ \\
\hline Fluid and electrolyte disorders & 1043 & 2.6 & 312 & 29.9 & 3766 & 9.5 & $<0.001$ \\
\hline Blood loss anemia & 209 & 0.5 & 30 & 14.4 & 4048 & 10.0 & 0.034 \\
\hline Deficiency anemia & 922 & 2.3 & 112 & 12.1 & 3966 & 9.9 & 0.026 \\
\hline Alcohol abuse & 1841 & 4.5 & 165 & 9.0 & 3913 & 10.0 & 0.136 \\
\hline Drug abuse & 57 & 0.1 & 5 & 8.8 & 4073 & 10.0 & 0.761 \\
\hline Psychoses & 292 & 0.7 & 25 & 8.6 & 4053 & 10.0 & 0.417 \\
\hline Depression & 1429 & 3.5 & 112 & 7.8 & 3966 & 10.1 & 0.006 \\
\hline
\end{tabular}

$P$ value comparing $\mathrm{IHM}$ between those with and without the condition 
Table 3 Comparison of performance indices for Artificial Neural Network models when using new data sets for predicting in hospital mortality rate in patients with T2DM after major LEA in Spain

\begin{tabular}{|c|c|c|c|c|c|}
\hline Indices & Description & Model 1 & Model 2 & Model 3 & Model 4 \\
\hline Accuracy rate & Ratio of instances correctly classified & 0.807 & 0.794 & 0.830 & 0.861 \\
\hline Error rate & Ratio of instances misclassified & 0.192 & 0.205 & 0.169 & 0.138 \\
\hline Sensitivity & Portion of actual positive which are predicted positive & 0.775 & 0.801 & 0.744 & 0.763 \\
\hline Specificity & Portion of actual negative predicted negative & 0.838 & 0.786 & 0.912 & 0.960 \\
\hline Precision & Portion of predicted positive which are actual positive & 0.821 & 0.787 & 0.888 & 0.951 \\
\hline Positive likelihood & Likelihood that a predicted positive is an actual positive & 4.794 & 3.756 & 8.476 & 19.23 \\
\hline Negative likelihood & Likelihood that a predicted negative is an actual negative & 3.733 & 3.962 & 3.569 & 4.06 \\
\hline F1 score & Harmonic mean of precision and sensitivity & 0.797 & 0.794 & 0.810 & 0.847 \\
\hline False positive rate & Portion of actual negative which are predicted positive & 0.161 & 0.213 & 0.087 & 0.039 \\
\hline False discovery rate & Portion of predicted positive which are actual negative & 0.178 & 0.212 & 0.111 & 0.048 \\
\hline False negative rate & Portion of actual positive which are predicted negative & 0.224 & 0.198 & 0.255 & 0.236 \\
\hline Negative predictive value & Portion of predicted negative which are actual negative & 0.795 & 0.800 & 0.790 & 0.800 \\
\hline Matthews correlation & $\begin{array}{l}\text { Correlation between the targets and the outputs. It takes a } \\
\text { value between }-1 \text { and }+1\end{array}$ & 0.615 & 0.588 & 0.668 & 0.737 \\
\hline Informedness & $\begin{array}{l}\text { Probability that the prediction method will make a correct } \\
\text { decision as opposed to guessing }\end{array}$ & 0.613 & 0.588 & 0.656 & 0.723 \\
\hline Markedness & Probability of predicting the classifier labels from the real classes. & 0.659 & 0.574 & 0.801 & 0.911 \\
\hline
\end{tabular}

Model 1: all discharge diagnosis included in the database. Model 2: all discharge diagnosis included in the database, except infectious diseases (ICD-9-CM codes 001 to 139). Model 3: comorbidities included in the Charlson Comorbidities Index. Model 4: comorbidities included in the Elixhauser Comorbidities Index

accuracy rate (0.8612 and 0.8307$)$ and ECI model performed better in terms of sensitivity, specificity and precision than CCI model (0.7634 vs $0.7444 ; 0.9602$ vs $0.9121 ; 0.9511$ vs 0.888 , respectively).

Compared with CCI model, ECI model showed a significantly better $(p=0.043)$ area under the ROC curve (91.7\% [95\% CI 90.3-93.0] vs 88.9\% [95\% CI; 87.5-90.2]) as can been seen in Fig. 1. The area under the curve for models 1 and 2 were 0.87 and 0.867 , respectively, showing that these models are less accurate to predict IHM after major LEAS using ANN.

The selection data set was also used to calculate the variable sensitive ratio (VSR). Table 4 presents the VSR values for the outcome variable (IHM) regarding $\mathrm{CCI}$ and
ECI comorbidities. In the ECI network for predicting IHM, the most sensitive parameter was age (VSR 1.451) followed by female sex (VSR 1.433), congestive heart failure (VSR 1.341), renal failure (VSR 1.274) and chronic pulmonary disease (VSR 1.266). Age, female sex, myocardial infarction, renal disease and congestive heart failure were the predictors of IHM with the CCI network. All VSR exceeded 1, which indicated that the network performs better when all variables were considered.

The sensitivity analysis, including all diabetic patients beside if codified as Type $1(n=1531 ; 3.61 \%)$ or Type 2 ( $n=40,857$; 96.39\%), showed that the AUC for the ECI was $90.1 \%$ (95\% CI 88.9-91.3) and for the CCI was 86.9\% (95\% CI 85.7\%-88.2\%) ( $p=0.026)$.
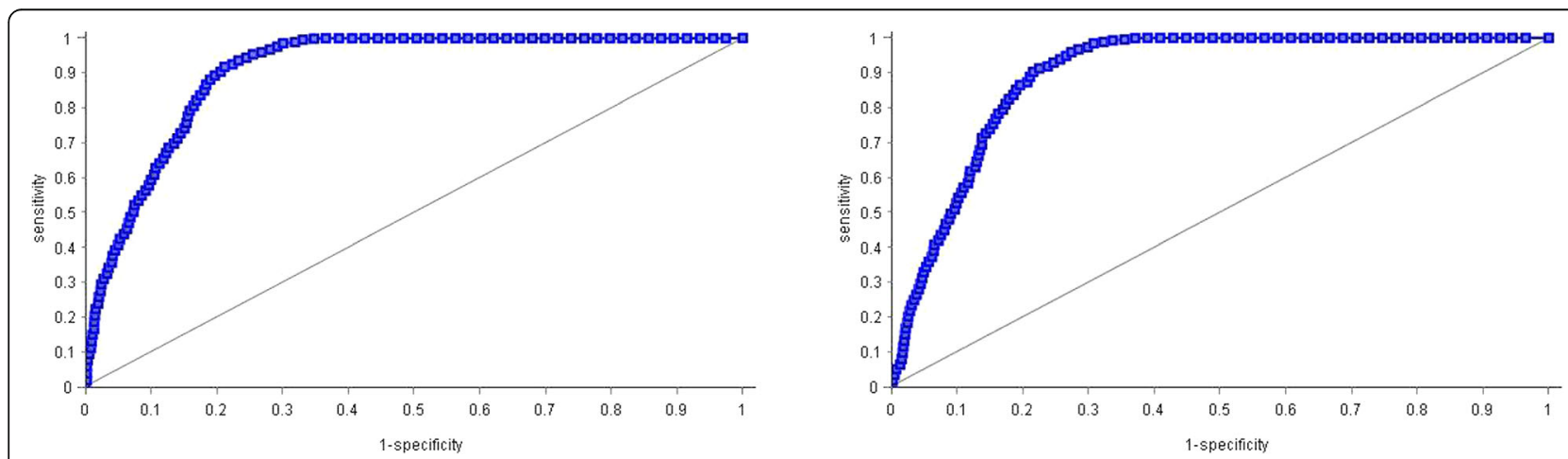

Fig. 1 Area under the ROC curve of the Charlson comorbidities index model and the Elixhauser comorbidities index model in predicting the in-hospital mortality rate after major LEA in patients with T2DM in Spain 
Table 4 Global sensitivity analysis of the Charlson comorbidities index model and the Elixhauser comorbidities index model in predicting the in-hospital mortality rate after major LEA in patients with T2DM in Spain

\begin{tabular}{|c|c|c|c|c|}
\hline \multirow[b]{2}{*}{ Variable ranking } & \multicolumn{2}{|l|}{ Charlson model } & \multicolumn{2}{|l|}{ Elixhauser model } \\
\hline & Variable & VSR & Variable & VSR \\
\hline $1 s t$ & Age & 1.577 & Age & 1.451 \\
\hline 2nd & Female & 1.559 & Female & 1.433 \\
\hline $3 r d$ & Myocardial infarction & 1.477 & Congestive heart failure & 1.341 \\
\hline 4th & Renal disease & 1.456 & Renal failure & 1.274 \\
\hline 5 th & Congestive heart failure & 1.447 & Chronic pulmonary disease & 1.266 \\
\hline 6th & Moderate or severe liver disease & 1.412 & Liver disease & 1.262 \\
\hline 7th & Metastatic solid tumor & 1.362 & Metastatic cancer & 1.246 \\
\hline
\end{tabular}

VSR Variable sensitivity ratio

\section{Discussion}

To our knowledge, this study is the first to use a nationwide population-based discharge database to train and test an ANN for predicting factors of IHM in type 2 diabetic patients after major LEAs. We assessed and compared the two most commonly used comorbidity risk adjustment models in surgery, the Charlson and Elixhauser measures, regarding their ability to predict in-hospital death [22].

Like in other surgical procedures it is necessary to appropriately adjust for T2DM patient risk, recognizing that the underlying nature of some patients' conditions may make them more likely than others to experience poor outcomes. Using ANNs we found that the ECI is a superior comorbidity risk-adjustment model for major lower extremity amputation in-hospital mortality compared with the CCI measure. Although differences in the area under the ROC curve between the two comorbidity-based measures were small, it has been noted that even slight improvements in area under the ROC curve for such indexes can translate into quantificable reductions in confounding bias [27]. Overall, the area under the ROC curve for inpatient mortality for the Charlson and Elixhauser comorbiditybased measures in our study were high and comparable to those described in other patient population [28, 29].

Major LEA in T2DM patients is associated with significant mortality. Our IHM of $10.0 \%$ is consistent with previously reported data ranging from $7 \%$ to $12.4 \%$ [7, 10, 30-33]. Investigation of underlying influences from health services, surgical decisions and patient motivations behind decisions to amputate might help to explain some of the differences in post-operative mortality rates between studies [34].

The effect of advancing age on IHM is also highlighted in this study, as has been well established by other authors $[7,10,30]$. Older age is associated with high prevalence of comorbid conditions, mainly cardiovascular and renal diseases, both of which are also associated with higher mortality rates [32, 35].
Despite having lower incidence rates of major LEAs several studies, including ours, suggest that women have higher mortality rates associated with diabetesrelated LEAs [36, 37]. In US have reported that women had higher IHM associated with diabetesrelated LEAS (37.7 IHM/1000 amputations vs. 29.7/ 1000 amputations [38]. Some previous research suggests higher LEA-associated cardiovascular disease mortality risk, including atherosclerotic complications, among women with LEAs [35, 38-40].

Several studies have evaluated specific comorbid diseases associated with reduced survival after major LEA [30-35, 38, 40]. Patients who needed major amputations suffered from a more severe cardiovascular disease than others [36]. Previous studies in Spain, significant risk factors for IHM were cardiac and respiratory complications and first episode of amputation [41]. Schofield et al. concluded that diabetic amputees have a greater risk of heart failure (OR: 2.26; 95\% CI 1.12-4.57) further amputation and death than nondiabetic amputees [12] and highlighted the need for a more aggressive approach in the management of cardiovascular risk factors in those who undergo amputation and have diabetes. A recent study in the Canadian population reported that predictors of prolonged hospital stay included cardiovascular risk factors, such as diabetes, hypertension, ischemic heart disease, congestive heart failure or hyperlipidemia [42].

Different studies have identified renal disease as a risk factor for a significantly lower long-term survival after a major LEA [6, 36, 43-46]. Recently, Assi et al. reported that patients with chronic kidney disease have higher risk (OR 2.27; 95\% CI 1.02-5.06) of postoperative longterm mortality and concluded that how CKD contributes to worse survival is unclear [31].

Other factor that has been found associated to mortality after amputations among people with diabetes was chronic pulmonary disease. Shah et al. demonstrated that several independent factors were detrimental to survival (at 24 months) including chronic obstructive pulmonary disease (hazard ratio $[\mathrm{HR}] 1.82, P=0.002$ ), 
dialysis dependence (HR 2.50, $P<0.001$ ), high cardiac risk (HR 2.20, $P<0.001$ ), and guillotine amputation (HR 2.49, $P=0.004$ ) [33].

The strength of our study lies in its large sample size and in the use of ANN models. Different studies indicated that ANN models can simultaneously process numerous variables and can consider outliers and nonlinear interactions among variables. Therefore, whereas conventional statistics reveal parameters that are significant only for the overall population, the ANN model includes parameters that are significant at the individual level even if they are not significant in the overall population [13-16].

One of the major limitations of our study is that our data source was the CMBD, which contains administrative discharge data for hospitalizations in Spain and uses information the physician included in the discharge report. In our data we have no information about detailed clinical variables like glycemic control or lifestyle variables like smoking habits. Nevertheless, the CMBD, are periodically audited and the validity of our dataset has been assessed and shown to be useful for health research [47].

Another possible limitation is that a misclassification bias may occur and some patients suffering T2DM may have been recorded as T1DM or vice versa. In our investigation we excluded T1DM patients because in our database only 1531 patients had the codes for T1DM recorded, representing the $3.61 \%$ of all mayor amputations analyzed. Furthermore, patients with T1DM were significantly younger (mean age 66.56 years vs. 73.77 years; $p<0.001$ ) and had less co-morbidities (mean CCI 1.25 vs. 1.39 and mean ECI 1.90 vs. 2.27; both $p<0.001$ ) than those with T2DM. However, the results of the sensitivity analysis showed very similar results suggesting that the misclassification bias would not affect the main conclusions of our study.

\section{Conclusions}

In conclusion, using ANN models we found that ECI method is a superior comorbidity risk-adjustment model for major LEA survival prediction in patients with T2DM than Charlson comorbidity. The global sensitivity analysis with the ECI model showed that the more predictors of IHM after major LEA procedure were older age followed by female sex, congestive heart failure, renal failure, chronic pulmonary disease, liver disease and metastatic cancer. The predictors analyzed in this study could be addressed in preoperative and postoperative health care of patients with T2DM candidates for major LEA.

\section{Abbreviations}

ANN: Artificial neural networks; CCl: Charlson Comorbidities Index; CMBD: Spanish National Hospital Discharge Database, Conjunto Mínimo Básico de Datos; ECI: Elixhauser comorbidity index; HR: Hazard ratio; ICD-9-
CM: International classification of diseases, ninth revision, clinical modification; IHM: In-hospital mortality; LEA: Lower extremity amputation LOHS: Length of hospital stay; SMHSSE: Spanish ministry of health, social services, and equality; T1DM: Type 1 diabetes mellitus; T2DM: Type 2 diabetes mellitus; VSR: Variable sensitive ratio

\section{Acknowledgements}

We would like to thank the SMHSSE for providing the records of the CMBD.

\section{Funding}

This study was funded by the FIS (Fondo de Investigaciones Sanitarias - Health Research Fund, grant no. PI13/00118 and grant no. PI16/00564, Instituto de Salud Carlos III) co-financed by the European Union through the Fondo Europeo de Desarrollo Regional (FEDER, "Una manera de hacer Europa"), and by the Grupo de Excelencia Investigadora URJC-Banco Santander No. 30VCPIGI03: Investigación traslacional en el proceso de salud-enfermedad (ITPSE).

\section{Availability of data and materials}

Data will not be shared because According to the contract signed with the Spanish Ministry of Health and Social Services that provided us the databases of the Spanish National Hospital Database, (Conjunto Mínimo Basico de Datos; (MBD) we cannot provide the databases to any other investigator and we have to destroy the databases once the investigation has been concluded. As a consequence of the previous we cannot upload the databases in any public repository. However, any investigator can apply for the databases filling the questionnaire available at: http://www.msssi.gob.es/ estadEstudios/estadisticas/estadisticas/estMinisterio/SolicitudCMBDdocs/ Formulario_Peticion_Datos_CMBD.pdf. In any case we consider that all relevant data are within the paper.

\section{Authors' contributions}

ALdA and RJG: researched data, contributed to the discussion, wrote the manuscript, and reviewed/edited the manuscript. VHB, RL and PMJ: researched data and reviewed/edited the manuscript. IJT, AAM and MASF: contributed to the discussion, wrote the manuscript, and reviewed/edited the manuscript. All authors reviewed and gave their final approval of the version to be submitted.

\section{Competing interests}

The authors declare that they have no competing interests.

\section{Consent for publication \\ Not applicable.}

\section{Ethics approval and consent to participate}

All data were anonymised and de-identified before the database was provided to the authors by the Spanish Ministry of Health, Social Services, and Equality (SMHSSE). The SMHSSE considered that our study protocol fulfilled all ethical requirements according to Spanish legislation and provided us with the database. Therefore, ethical approval was not required.

\section{Author details}

${ }^{1}$ Preventive Medicine and Public Health Teaching and Research Unit, Health Sciences Faculty, Rey Juan Carlos University, Avda. de Atenas s/n, 28922 Alcorcón, Comunidad de Madrid, Spain. ${ }^{2}$ Research \& Development Department, Artelnics, Spain. ${ }^{3}$ Dirección Técnica de Docencia e Investigación, Gerencia Atención Primaria, Madrid, Comunidad de Madrid, Spain.

Received: 1 July 2016 Accepted: 16 November 2016

Published online: 22 November 2016

\section{References}

1. Eskelinen E, Eskelinen A, Alback A, Lepäntalo M. Major amputation incidence decreases both in non-diabetic and in diabetic patients in Helsinki. Scand J Surg. 2006;95:185-9.

2. Ikonen TS, Sund R, Venermo M, Winell K. Fewer major amputations among individuals with diabetes in Finland in 1997-2007: a population-based study. Diabetes Care. 2010;33:2598-603.

3. Kennon B, Leese GP, Cochrane L, Colhoun H, Wild S, Stang D, et al. Reduced incidence of lower-extremity amputations in people with diabetes in Scotland: a nationwide study. Diabetes Care. 2012;35:2588-90. 
4. Lombardo FL, Maggini M, De Bellis A, Seghieri G, Anichini R. Lower extremity amputations in persons with and without diabetes in Italy: 2001-2010. PLoS ONE. 2014;9:e86405.

5. Jørgensen ME, Almdal TP, Faerch K. Reduced incidence of lower-extremity amputations in a Danish diabetes population from 2000 to 2011. Diabet Med. 2014:31:443-7.

6. Mayfield JA, Reiber GE, Maynard C, Czerniecki JM, Caps MT, Sangeorzan BJ Survival following lower-limb amputation in a veteran population. J Rehabil Res Dev. 2001;38:341-5.

7. Icks A, Scheer M, Morbach S, Genz J, Haastert B, Giani G, et al. Timedependent impact of diabetes on mortality in patients after major lower extremity amputation: survival in a population-based 5-year cohort in Germany. Diabetes Care. 2011;34:1350-4.

8. Lopez-de-Andres A, Jiménez-García R, Aragón-Sánchez J, Jiménez-Trujillo I, Hernández-Barrera V, Méndez-Bailón M, et al. National trends in incidence and outcomes in lower extremity amputations in people with and without diabetes in Spain, 2001-2012. Diabetes Res Clin Pract. 2015;108:499-507.

9. López-de-Andrés A, Martínez-Huedo MA, Carrasco-Garrido P, HernándezBarrera V, Gil-de-Miguel A, Jiménez-García R. Trends in lower-extremity amputations in people with and without diabetes in Spain, 2001-2008. Diabetes Care. 2011;34:1570-6.

10. Karam J, Shepard A, Rubinfeld I. Predictors of operative mortality following major lower extremity amputations using the National Surgical Quality Improvement Program public use data. J Vasc Surg. 2013;58:1276-82.

11. Wise ES, McMaster Jr WG, Williamson K, Wergin JE, Hocking KM, Brophy CM. Preoperative Predictors of 30-Day Mortality and Prolonged Length of Stay after Above-Knee Amputation. Ann Vasc Surg. 2016;31:124-33.

12. Schofield CJ, Libby G, Brennan GM, MacAlpine RR, Morris AD, Leese GP, et al. Mortality and hospitalization in patients after amputation: a comparison between patients with and without diabetes. Diabetes Care. 2006;29:2252-6.

13. Cross SS, Harrison RF, Kennedy RL. Introduction to neural networks. Lancet. 1995;346:1075-9.

14. Bartosch-Harlid A, Andersson B, Aho U, Nilsson J, Andersson R. Artificial neural networks in pancreatic disease. Br J Surg. 2008;95:817-26.

15. Ansari D, Nilsson J, Andersson R, Regnér S, Tingstedt B, Andersson B. Artificial neural networks predict survival from pancreatic cancer after radical surgery. Am J Surg. 2013;205(1):1-7.

16. Karthikesalingam A, Attallah O, Ma X, Bahia SS, Thompson L, Vidal-Diez A, et al. An Artificial Neural Network Stratifies the Risks of Reintervention and Mortality after Endovascular Aneurysm Repair; a Retrospective Observational study. PLoS ONE. 2015;10:e0129024

17. Instituto Nacional de Gestión Sanitaria, Ministerio de Sanidad, Servicios Sociales e Igualdad: Conjunto Mínimo Básico de Datos, Hospitales del INSALUD. http://www.ingesa.msssi.gob.es/estadEstudios/documPublica/pdf/ CMBD-2001.pdf . Accessed 6 Oct 2015.

18. Muñoz-Rivas N, Méndez-Bailón M, Hernández-Barrera V, de Miguel-Yanes JM, Jiménez-García R, Esteban-Hernández J, et al. Time Trends in Ischemic Stroke among Type 2 Diabetic and Non-Diabetic Patients: Analysis of the Spanish National Hospital Discharge Data (2003-2012). PLoS ONE. 2015;10:e0145535.

19. Lopez-de-Andrés A, Jiménez-García R, Jiménez-Trujillo I, Hernández-Barrera V, de Miguel-Yanes JM, Méndez-Bailón M, et al. Incidence, surgical procedures, and outcomes of hip fracture among elderly type 2 diabetic and non-diabetic patients in Spain (2004-2013). Osteoporos Int. 2016;27:605-16.

20. Bishop C. Neural networks for pattern recognition. Oxford University Press, 1995. http://cs.du.edu/ mitchell/mario_books/Neural_Networks_for_ Pattern_Recognition__CChristopher_Bishop.pdf. Accessed 6 Oct 2015.

21. Anders U, Korn O. Model selection in neural networks. ZEW Discusson Papers 1996: 96-21. https://www.econstor.eu/bitstream/10419/29449/1/ 257954961.pdf . Accessed 6 Oct 2016.

22. Quan H, Sundararajan V, Halfon P, Fong A, Burnand B, Luthi JC, et al. Coding algorithms for defining comorbidities in ICD-9-CM and ICD-10 administrative data. Med Care. 2005;43:1130-9.

23. Vuk M, Curk T. ROC curve, lift chart and calibration plot. Metodoloski zvezki. 2006:3:89-108

24. Shi HY, Hwang SL, Lee KT, Lin CL. In-hospital mortality after traumatic brain injury surgery: a nationwide population-based comparison of mortality predictors used in artificial neural network and logistic regression models. J Neurosurg. 2013;118:746-52

25. Epidat: programa para análisis epidemiolóxico de datos. Versión 4.2. Consellería de Sanidade, Xunta de Galicia, España; Organización Panamericana da saúde (OPS-OMS); Universidade CES, Colombia. 2016
26. DeLong ER, DeLong DM, Clarke-Pearson DL. Comparing the areas under two or more correlated receiver operating curves: a nonparametric approach. Biometrics. 1988:44:837-45.

27. Schneeweiss S, Seeger JD, Maclure M, Wang PS, Avorn J, Glynn J. Performance of comorbidity scores to control for confounding in epidemiologic studies using claims data. Am J Epidemiol. 2001;154:854-64.

28. Menendez ME, Neuhaus V, van Dijk CN, Ring D. The Elixhauser comorbidity method outperforms the Charlson index in predicting inpatient death after orthopaedic surgery. Clin Orthop Relat Res. 2014;472:2878-86.

29. Lieffers JR, Baracos VE, Winget M, Fassbender K. A comparison of Charlson and Elixhauser comorbidity measures to predict colorectal cancer survival using administrative health data. Cancer. 2011;117:1957-65.

30. Papazafiropoulou A, Tentolouris N, Soldatos RP, Liapis CD, Dounis E, Kostakis AG, et al. Mortality in diabetic and nondiabetic patients after amputations performed from 1996 to 2005 in a tertiary hospital population: a 3-year follow-up study. J Diab Complications. 2009;23:7-11.

31. Assi R, Al Azzi Y, Protack CD, Williams WT, Hall MR, Wong DJ, et al. Chronic kidney disease predicts long-term mortality after major lower extremity amputation. N Am J Med Sci. 2014;6(7):321-7.

32. Scott SW, Bowrey S, Clarke D, Choke E, Bown MJ, Thompson JP. Factors influencing short- and long-term mortality after lower limb amputation. Anaesthesia. 2014;69(3):249-58.

33. Shah SK, Bena JF, Allemang MT, Kelso R, Clair DG, Vargas L, et al. Lower extremity amputations: factors associated with mortality or contralateral amputation. Vasc Endovasc Surg. 2013;47(8):608-13.

34. Fortington LV, Geertzen JH, van Netten JJ, Postema K, Rommers GM, Dijkstra PU. Short and long term mortality rates after a lower limb amputation. Eur J Vasc Endovasc Surg. 2013;46(1):124-31.

35. Resnick HE, Carter EA, Lindsay R, Henly SJ, Ness FK, Welty TK, et al. Relation of lower-extremity amputation to all-cause and cardiovascular disease mortality in American Indians: the Strong Heart Study. Diabetes Care. 2004;27:1286-93.

36. Hoffmann M, Kujath P, Flemming A, Proß M, Begum N, Zimmermann M, et al. Survival of diabetes patients with major amputation is comparable to malignant disease. Diab Vasc Dis Res. 2015;12:265-71.

37. Peek ME. Gender differences in diabetes-related lower extremity amputations. Clin Orthop Relat Res. 2011:469:1951-5.

38. Lavery LA, van Houtum WH, Armstrong DG, Harkless LB, Ashry HR, Walker SC. Mortality following lower extremity amputation in minorities with diabetes mellitus. Diabetes Res Clin Pract. 1997;37(1):41-7.

39. Pyörälä K, Laakso M, Uusitupa M. Diabetes and atherosclerosis: an epidemiologic view. Diabetes Metab Rev. 1987;3:463-524.

40. Hambleton IR, Jonnalagadda R, Davis CR, Fraser HS, Chaturvedi N, Hennis AJ. All-cause mortality after diabetes-related amputation in Barbados: a prospective case-control study. Diabetes Care. 2009;32:306-7.

41. Aragón-Sánchez J, Hernández-Herrero MJ, Lázaro-Martínez JL, QuintanaMarrero Y, Maynar-Moliner M, Rabellino M, et al. In-hospital complications and mortality following major lower extremity amputations in a series of predominantly diabetic patients. Int J Low Extrem Wounds. 2010;9:16-23.

42. Kayssi A, de Mestral C, Forbes TL, Roche-Nagle G. A Canadian populationbased description of the indications for lower-extremity amputations and outcomes. Can J Surg. 2016;59:99-106.

43. Ghanassia E, Villon L. Thuan Dit Dieudonné JF, Boegner C, Avignon A, Sultan A. Long-term outcome and disability of diabetic patients hospitalized for diabetic foot ulcers: a 6.5-year follow-up study. Diabetes Care. 2008;31:1288-92.

44. Morbach S, Furchert H, Gröblinghoff U, Hoffmeier H, Kersten K, Klauke GT, et al. Long-term prognosis of diabetic foot patients and their limbs: amputation and death over the course of a decade. Diabetes Care. 2012;35:2021-7

45. Aulivola B, Hile CN, Hamdan AD, Sheahan MG, Veraldi JR, Skillman JJ, et al. Major lower extremity amputation: outcome of a modern series. Arch Surg. 2004;139:395-9.

46 Feinglass J, Pearce WH, Martin GJ, Gibbs J, Cowper D, Sorensen M, et al. Postoperative and late survival outcomes after major amputation: Findings from the department of veterans affairs national surgical quality improvement program. Surgery. 2001;130:21-9.

47 Ribera A, Marsal JR, Ferreira-González I, Cascant P, Pons JM, Mitjavila F, et al. Predicting in-hospital mortality with coronary bypass surgery using hospital discharge data: comparison with a prospective observational study. Rev Esp Cardiol. 2008;61:843-52. 